\title{
Enhancement of photoconductivity by carrier screening effect in $n$-GaSb/n-InAs/p-GaSb heterostructure with single deep quantum well
}

(C) L.V. Danilov, M.P. Mikhailova, R.V. Levin, G.G. Konovalov, E.V. Ivanov,

I.A. Andreev, B.V. Pushnyi, G.G. Zegrya

loffe Institute,

194021 St. Petersburg, Russia

E-mail: danleon84@mail.ru

$n$-GaSb/n-InAs/ $p$-GaSb heterostructure with a single InAs QW was grown for the first time by MOVPE. Photocurrent spectra were obtained at reverse bias in the range from 0 to $0.8 \mathrm{~V}$. It was shown that the photocurrent increases nonlinearly. The maximum of differential photoconductivity is archived at low applied voltage up to $0.2 \mathrm{~V}$. This effect was explained by electrostatic screening of electrons localized in QW.

\section{Acknowledgements}

This work was partially supported by grants RFBR No 16-08-01130 and 15-02-03151. 